\title{
Professional Development Opportunities
}

compiled by Cynthia Snell

\section{METADATA}

\section{Metadata and Description for Digital Special Collections}

Methods and standards for metadata and description for unique digital collections are varied and present digital curators, catalogers and metadata librarians with a wide array of options, which can at times seem daunting. This course is designed to give the student an overview of current standards, schemas and applications of medatada models designed for the description and organization of digital collections, whether they be materials in an institutional repository or digital special collections.

September 7-October 4, 2020; March 1-28, 2021

$\$ 175$

\section{Using OpenRefine for Library Metadata}

OpenRefine is a free open-source tool that makes editing messy metadata easier through clustering, faceting, advanced find and replace scripting, and linked data reconciliation in a spreadsheet-like environment. In addition to cleaning up metadata, OpenRefine's linked data and URL building tools can extend metadata through databases and API calls.

October 5-November 1, 2020

$\$ 175$ 